\title{
O RECONHECIMENTO DA NATUREZA COMO SUJEITO DE DIREITOSNAS CONSTITUIÇÕES DO EQUADOR E DA BOLÍVIA
}

\author{
Deilton Ribeiro Brasil * \\ Carolina Furtado Amaral ${ }^{* *}$ \\ Xenofontes Curvelo Piló****
}

\section{RESUMO:}

Esta pesquisa tem como objetivo fazer reflexões sobre a possibilidade de amparo jurídico ao se atribuira natureza personalidade jurídica. $O$ texto propõe, fazendo-se uso do método indutivo e de pesquisa bibliográfica, uma abordagem da proteção dos direitos da natureza conferidos nas Constituições do Equador (2008) e da Bolívia (2009) bem como investigar de que modo as experiências jurídicas equatoriana e boliviana podem contribuir para o reconhecimento da natureza como sujeito de direitos e ao mesmo tempo garantir o efetivo direito de todos de usufruir o meio ambiente ecologicamente equilibrado.

PALAVRAS-CHAVE: Reconhecimento de personalidade jurídica; Bens Ambientais; Constituição do Equador; Constituição da Bolívia; Proteção ambiental.

\section{THE ACKNOWLEDGEMENT OF NATURE AS SUBJECT OF RIGHTS IN THE ECUADOR AND BOLIVIA CONSTITUTION}

\begin{abstract}
:
This research aims to reflect on the possibility of legal protection when assigning the legal entity to nature. The text proposes, using the inductive method and bibliographic research, a broad approach to the protection of the rights of nature conferred in the Constitutions of Ecuador (2008) and Bolivia (2009) as well as investigating how Ecuadorian and Bolivian legal experiences can contribute to the recognition of nature as a subject of rights and at the same time guarantee the effective right of all to enjoy the ecologically balanced environment.
\end{abstract}

KEYWORDS: Acknowledgement of legal entity; Environmental assets; Ecuador's Constitution; Bolivia's Constitution; Environmental protection

\section{INTRODUÇÃO}

\footnotetext{
* Pós-Doutor em Direito pela Universitàdegli Studi di Messina, Itália. Doutor em Direito pela UGF-RJ. Professor da Graduação e do PPGD Mestrado e Doutorado em Proteção dos Direitos Fundamentais da Universidade de Itaúna-MG e das Faculdades Santo Agostinho-FASASETE-AFYA. E-mail: deilton.ribeiro@terra.com.br

${ }^{* *}$ Mestranda do PPGD - Mestrado e Doutorado em Proteção dos Direitos Fundamentais da Universidade de Itaúna-MG. Procuradora da Prefeitura Municipal de Ipanema-MG. E-mail: caroldireito08@ hotmail.com

${ }^{* * *}$ Mestrando do PPGD - Mestrado e Doutorado em Proteção dos Direitos Fundamentais da Universidade de Itaúna-MG. Advogado. E-mail: xenopilo@yahoo.com.br
} 
A compreensão da natureza como sujeito de direitos, corresponde à corrente ecocêntrica. Nessa teoria, o ambiente e a natureza são o eixo central das temáticas ambientais. Essa corrente influenciou a Carta da Natureza das Nações Unidas de 1982, a qual compreende que a espécie humana é parte da natureza, e que a vida necessita de funcionamento ininterrupto dos sistemas naturais, e adverte que toda a forma de vida é única e deve ser respeitada, independentemente de sua serventia ao ser humano (GARZÒN, 2017, p. 15).

$\mathrm{O}$ artigo é dividido em cincopartes. A primeira parte é a introdução com destaque para a metodologia adotada no desenvolvimento da pesquisa. A segunda parte é referente anatureza como sujeito de direitos nas Constituições do Equador e da Bolívia. A terceira parte é referente ao princípio 10 da Declaração do Rio sobre meio ambiente e desenvolvimento.Por último, na quarta parte serão apresentadas as considerações finais sobre a temática colocada em relevo ao longo do trabalho bem como na quintaparte serão apresentadas as referências utilizadas.

O método utilizado para a realização do trabalho foi o indutivo com a abordagem de categorias consideradas fundamentais para o desenvolvimento do tema sobre a natureza como sujeito de direitos nas Constituições do Equador e da Bolívia em defesa dos direitos da natureza. Os procedimentos técnicos utilizados na pesquisa para coleta de dados foram essencialmente a pesquisa bibliográfica.

O levantamento bibliográfico forneceu as bases teóricas e doutrinárias a partir de livros e textos de autores de referência, tanto nacionais como estrangeiros. Enquanto o enquadramento bibliográfico utiliza-se da fundamentação dos autores sobre um assunto, o documental articula materiais que não receberam ainda um devido tratamento analítico. A fonte primeira da pesquisa é a bibliográfica que instruiu a análise da legislação constitucional e a infraconstitucional, bem como a doutrina que informa os conceitos de ordem dogmática.

\section{O RECONHECIMENTO DA NATUREZA COMO SUJEITO DE DIREITOS NAS CONSTITUIÇÕES DO EQUADOR E BOLÍVIA}

Para que se possa apreender adequadamente a natureza como um sujeito de direitos é importante determinar o que se entende por sujeito de direito, neste ato analisado sob dois enfoques. Desta maneira, considerando que o direito regulamenta o comportamento das 
pessoas, em regra, considera os seres humanos - sujeitos de direito. Assim, o termo sujeito advém do latim subjectus que indica o indivíduo ou o grupo que é submetido ao poder de outrem, em uma relação de subordinação. Entretanto, na filosofia ocidental a palavra - sujeito adquiriu outro sentido, quase que oposto, visto que passou a indicar o ser humano como ser que consegue raciocinar e agir livremente, capaz de dominar as coisas e o mundo, ou seja, o sujeito passa a dominar os objetos. No âmbito jurídico, o termo sujeito de direito detém, em regra, o segundo significado, de maneira que indica o titular de um direito, isto é, a pessoa ou entidade que tem a capacidade para adquirir um direito ou assumir uma obrigação, impondo a sua vontade e preservando os seus interesses. Somente pode ser sujeito de direitos quem for reconhecido como tal pelo ordenamento jurídico, por meio de normas que lhe conferem referida capacidade (DIMOULIS, 2013, p. 215).

A Constituição do Equador foi aprovada mediante referendo popular e entrou em vigor no dia 20 de outubro de 2008. Em seu preâmbulo, celebra a natureza ou Pacha Mama, vital para a existência humana, e invoca a sabedoria de todas as culturas que enriquecem a sociedade como tal.

No capítulo sétimo consagra os direitos da Pacha Mama, dentre os quais se insere o direito de restauração, o respeito integral à sua existência e à manutenção e regeneração de seus ciclos vitais, estrutura, funções e processos evolutivos, podendo toda e qualquer pessoa, independente de sua nacionalidade, exigir da autoridade pública seu cumprimento. Prevê, ainda, o dever do Estado de incentivar a proteção da natureza e a promoção do respeito a todos os elementos que formam um ecossistema.

Elemento cíclico do espaço e tempo, Pacha Mama congloba os vivos, os mortos, e os que ainda estão para nascer.A extensão do significado do termo evoca muito mais que a noção de mãe querida, atrelada desde a colonização andina à Virgem Maria dos católicos.De todo modo, atualmente é reconhecida como a "padroeira espiritual das correntes ambientalistas que começam a surgir na Bolívia.” É ela o símbolo visível da integração das gerações humanas e da Natureza (CAMARGO, 2006, p. 88-89).

O artigo 10 da Constituição Equatoriana preceitua que:

Artículo 10: Las personas, comunidades, pueblos, nacionalidades y colectivosson titulares y gozarán de losderechosgarantizadosenlaConstitución y enlos instrumentos internacionales. La naturaleza será sujeto de aquellos derechos que Le reconozca la Constitución (ECUADOR, 2008). 
No citado dispositivo resta expresso a atribuição de personalidade jurídica à natureza, ou melhor, o reconhecimento da natureza como sujeito não humano despersonificado.

Despersonificado porque os direitos, longe de serem amplos, são aqueles que a Constituição equatoriana prevê nos artigos 71 e 72 :

\begin{abstract}
Artículo 71:La naturaleza o Pacha Mama, donde se reproduce y realiza la vida, tiene derecho a que se respete integralmente su existencia y El mantenimiento y regeneración de sus ciclos vitales, estructura, funciones y procesos evolutivos.

Toda persona, comunidad, pueblo o nacionalidad podrá exigir a la autoridad pública el cumplimiento de los derechos de la naturaleza. Para aplicar e interpretar estos derechos se observaranlos principios establecidos en la Constitución, en lo que proceda.

El Estado incentivará a las personas naturales y jurídicas, y a los colectivos, para que protejan la naturaleza, y promoverá el respeto a todos los elementos que forman un ecosistema.
\end{abstract}

Artículo 72: La naturaleza tiene derecho a la restauración. Esta restauración será independiente de la obligación que tienen el Estado y las personas naturales o jurídicas de indemnizar a los individuos y colectivos que dependan de los sistemas naturales afectados.

En los casos de impacto ambiental grave o permanente, incluidos los ocasionados por la explotación de los recursos naturales no renovables, el Estado establecerá los mecanismos más eficaces para alcanzar la restauración, y adoptará las medidas adecuadas para eliminar o mitigar las consecuencias ambientales nocivas.

Artículo 73: El Estado aplicará medidas de precaución y restricción para las actividades que puedan conducir a la extinción de especies, la destrucción de ecosistemas o la alteración permanente de los ciclos naturales. Se prohíbe la introducción de organismos y material orgánico e inorgánico que puedan alterar de manera definitiva el patrimonio genético nacional.

Artículo 74: Las personas, comunidades, pueblos y nacionalidades tendrán derecho a beneficiarse del ambiente y de las riquezas naturales que les permitan el buen vivir. Los servicios ambientales no serán susceptibles de apropiación; su producción, prestación, uso y aprovechamiento serán regulados por el Estado (ECUADOR, 2008)

Tais dispositivos são completados pelo artigo 397 que estabelece a responsabilidade do Estado de atuar de maneira imediata e subsidiária em casos de danos ambientais, visando garantir a saúde e a restauração dos ecossistemas.

Jesús Conde Antequera (2004, p. 94) explica que:

La restauración ambiental desde una perspectiva ecológica habrá de definirse como la restauración de la interacción o interrelación ecológica, de la funcionalidad ambiental que los elementos ambientales dañados han dejado de aportar a consecuencia del daño. Restauración que consistiría, en la devolución, en la medida posible, al suelo, aire y agua, a la fauna, flora y condiciones ambientales de 
desarrollo de tales especies, de las propiedades que se hubieran perdido o alterado, de tal forma que los recursos deteriorados y el sistema ecológico recuperan su funcionalidad alterada.

O terceiro direito tutelado, inserto no artigo 73 , diz respeito a medidas de precaução e restrição que o Estado deve aplicar frente a atividades que possam conduzir a extinção de espécies, a destruição dos ecossistemas e a alteração permanente dos ciclos naturais. Também proíbe a introdução de elementos que possam alterar de maneira definitiva o patrimônio genético nacional; é dizer, proíbe-se a introdução de organismos geneticamente modificados.

Para Rene Patricio Bedón Garzón (2017, p. 9), tal dispositivo “declara al país libre de cultivos y semillas transgénicas, siendo posible su introducción únicamente de forma excepcional cuando haya sido declarado de interés nacional por la Asamblea Nacional a petición del Presidente de la República.’Tal direito encontra seu fundamento no princípio "pro natura”, segundo o qual, em virtude da presunção a favor da proteção da natureza, é preferível equivocar-se tomando medidas do que não o fazendo (GARZÓN, 2017, p. 9).

Por seu turno, o artigo 74 da Constituição do Equador consagra o direito de não apropriação de serviços ambientais, segundo o qual ninguém, nem sequer o Estado, pode se apropriar dos serviços ambientais. O dispositivo estabelece também que a produção, prestação, uso e aproveitamento dos serviços ambientais será regulado pelo Estado. O Código Orgánico General de Procesos Ecuatoriano, em vigor desde maio de 2016, define os serviços ambientais nos seguintes termos:

\begin{abstract}
Los beneficios que las poblaciones humanas obtienen directa e indirectamente de las funciones de la biodiversidad (ecosistemas, especies y genes), especialmente ecosistemas y bosques nativos y de plantaciones forestales y agroforestales. Los servicios ambientales se caracterizan porque no se gastan ni transforman en el proceso, pero generan utilidad al consumidor de tales servicios; y, se diferencian de los bienes ambientales, por cuanto estos últimos son recursos tangibles que son utilizados por el ser humano como insumo de la producción o en el consumo final, y que se gastan o transforman en el proceso (ECUADOR, 2008).
\end{abstract}

A partir de uma leitura dos dispositivos depreende-se que há direito da Natureza a ser respeitado, seja no que concerne à sua existência e proteção, seja nos aspectos ligados à sua regeneração. A natureza não é mais mero objeto. Vale por si só. E como sujeito, embora não esteja autorizado a fazer tudo o que a lei não proíbe, tem ao menos três direitos listados na Constituição do Equador: a) à existência; b) à integridade; e c) à regeneração em caso de dano (OLIVEIRA, 2013).

No entanto, ao tratar da personalidade jurídica da natureza, quando se fala em vida e de seu valor intrínseco, refere-se ao conceito despido de tecnicidade, pois "além de 
indivíduos, espécies e culturas, abrange também ecossistemas, paisagens, rios” (GOUVEIA, 2013, p. 64). É nesse sentido que a Constituição do Equador se refere à natureza, conjunto de elementos que compõem os ecossistemas. Portanto, a princípio enquadra-se no conceito de ente natural qualquer elemento ou conjunto de elementos orgânicos ou inorgânicos que contribuem para a subsistência dos ecossistemas (GUSSOLI, 2014, p. 16).

Dessa forma, a Constituição do Equador promove a natureza a sujeito de direitos e prevê deveres expressos de precaução, quanto à adoção de medidas pelo Estado para evitar impactos negativos.

Outro aspecto da Constituição Equatoriana é a inclusão do bem viver ou sumak kawsay, do quéchua, como uma aspiração de convivência cidadã, em diversidade e harmonia com a natureza, conforme seu preâmbulo, reconhecendo, no artigo 14, o direito de todos a viver em um ambiente sadio e ecologicamente equilibrado, garantindo a sustentabilidade e o próprio sumak kawsay que é a expressão de uma forma ancestral de ser e de estar no mundo. Expressa, de certa maneira, as proposições teóricas de décroissance deLatouche (2004, p. 109), de convívio de Ivan Illich (1974, p. 22) e de ecologia profunda de Arnold Naess (1994) que possui, dentre seus pressupostos, a representação da natureza como um sujeito de direitos, não mero objeto, reconhecendo àquela dignidade e direitos fundamentais (STEIGLEDER, 2011 p. 72).O buen vivir relaciona-se às propostas de descolonização desenvolvidas por Quijano (1992), Santos (2004) e Lander (2005).

Como princípio constitucional, o buen vivir surge para orientar a efetivação e a concretização de toda a Constituição e de toda a ordem jurídica fundamental do povo equatoriano. O texto constitucional faz menção ao buen vivir em seu preâmbulo e trata também dos derechos del buen vivir, que são: água e alimentação (artigos 12 e 13), ambiente sadio (artigos 14 e 15), comunicação e informação (artigos 16 a 20), cultura e ciência (artigos 21 a 25), educação (artigos 26 a 29), habitat e vivenda (artigos 30 e 31), saúde (artigo 32), trabalho e seguridade social (artigos 33 e 34).

Assim, o termo bem viver, que surge como uma perspectiva com capacidade de dar sentido para a realização das liberdades públicas e privadas, e tem como pressuposto expandir e qualificar essas liberdades frente às limitações históricas, coletivas e individuais. O bem viver se resume à concreta aplicação das liberdades, por meio de ações que permitam o seu real exercício, aos meios econômicos, educativos, políticos, dentre outros (MANCE, 2016). 
A estratégia do bem viver visa a inserção de um novo modelo econômico, que representa uma nova forma política e uma cultura solidária, que seja capaz de organizar a sociedade de forma que as liberdades sejam eficientes a ponto de garantir a todas as pessoas as mediações materiais, políticas e educativas, com a realização da singularidade e a sustentação do bem comum. Isso significa a reestruturação do Estado e a reivindicação dos direitos humanos (MANCE, 2016).

Em outras palavras, o pressuposto do bem viver é a ética da suficiência para a comunidade, na qual a produção e o consumo não podem ultrapassar o que o ecossistema consegue suportar. O ser humano está inserido num contexto maior, no qual se busca a harmonia dos seres que habitam a Pacha Mama. O resgate destas dimensões não admite a qualidade de vida reduzida à posse e acumulação de bens materiais, que é predominante no Ocidente (BOFF, 2013).

O Estado de bem viver é a assunção do integral respeito pela diversidade humana e da absoluta necessidade de integração com o meio ambiente em que vive, entendendo-se que a destruição e o esgotamento da natureza levarão, com absoluta certeza, senão a sua completa extinção, a uma vida despregada de dignidade, o que se cumpre a todo custo evitar (CLAVERO, 2014, p. 208-209).

A necessidade de transposição do paradigma do Estado de Bem Estar para o novel modelo do Estado de bem viver está firmemente lastreada, insista-se, no incontroverso fato de que o ser humano não detém em relação as mais diversas formas de vida a condição de dominus, mas sim de elemento integrante e integrador, em verdadeira condição de interdependência. As prestações materiais que envolvem o Estado de BemEstar obviamente são de implemento indispensável a dignidade humana, porém são finitas e esgotáveis, momento em que, percebendo a necessidade de interação protetiva e respeitosa com a natureza e todas as outras formas de vida, as referidas prestações, razoáveis e proporcionalmente equilibradas, perduram no tempo, permitindo não só a manutenção da dignidade humana mas, beneficamente, de toda a vida (BAHIA; TOLEDO; TOLEDO, 2018, p. 141).

Sumak significa a plenitude, o sublime, excelente, magnífico. Kawsay refere-se à vida, em uma concepção dinâmica. Portanto sumak kawsay pode ser compreendido como a vida em plenitude. É a vida em excelência material e espiritual. O sublime expressa a harmonia, o equilíbrio interno e externo de uma comunidade (ACOSTA, 2008). 
Dessa forma, o conceito do sumak kawsay propõe uma oposição à lógica do capitalismo neoliberal que imprime uma concepção de vida boa atrelada à necessidade de consumir sempre mais e mais bens. Exaltar a convivência harmônica do homem e da natureza é um dos eixos centrais dessa proposta (POLI, 2015, p. 25).

O processo constituinte da Bolívia inicia-se em 2006, após a instalação do governo de Evo Morales, sendo que o texto final da constituição foi aprovado, em 25 de janeiro de 2009, por mais de 61,43\% dos eleitores bolivianos participantes do Referendo Constitucional. Foi a partir dos debates acerca da plurinacionalidade que a nova constituição boliviana foi estruturada(LEONEL JÚNIOR, 2015, p. 114)

A Constituição Boliviana destaca-se por reconhecer em seu texto o pluralismo, demonstrando um rompimento com o modelo de estado liberal opressor e abrindo espaço para um Estado quereconhece a diversidade cultural e as mais diferentes manifestações de seus povos, elucidado pelo artigo $5^{\circ}$, inciso I,

\begin{abstract}
Artículo 5: Son idiomas oficiales del Estado el castellano y todos los idiomas de las naciones y pueblos indígena originario campesinos, que son el aymara, araona, baure, bésiro, canichana, cavineño, cayubaba, chácobo, chimán, ese ejja, guaraní, guarasu'we, guarayu, itonama, leco, machajuyai-kallawaya, machineri, maropa, mojeño-trinitario, mojeño-ignaciano, moré, mosetén, movima, paca-wara, puquina, quechua, sirionó, tacana, tapiete, toromona, uru-chipaya, weenhayek, yaminawa, yu-ki, yuracaré zamuco (BOLIVIA, 2009)
\end{abstract}

Há o reconhecimento como idioma pátrio o castelhano e todos os outros idiomas provenientes de nações e povos indígenas. Ainda, destaca-se por ser uma constituição demasiadamente ampla, com 411 artigos, prevendo não somente um extenso rol de direitos, mas também maneiras de execução e viabilidade, bem como uma maior acessibilidade dos direitos aos povos (MAGRO; SIGNOR; AQUINO, 2018, p. 67).

A presença desses povos e de suas manifestações as sociedade plurinacional possibilita um resgate histórico dos direitos e dos valores, contribuindo para a formação da plurinacionalidade, inclusive como modo de combate à dominação cultural e de quebra das estruturas que são, ainda, resquícios dos processos de colonização latino-americana (ARKONADA et al; 2012, p. 12-13).

Além da plurinacionalidade presente no Estado boliviano, uma outra característica apresentou-se como indispensável para a elaboração da sua Constituição pluralista: a participação popular. A Assembleia Constituinte responsável pela elaboração do texto 
constitucional foi originada por uma revolução social, o que garantiu a participação popular, possibilitando a posterior inserção das demandas locais de cada grupo social e étnico na Constituição. Essa organização, além de democrática, possui um viés extremamente inclusivo, uma vez que, em um Estado nacional (uno), todos que não se identificam com a identidade nacional - projetada pelo capital - sentem-se não pertencentes aos espaços sociais, ou seja, são imobilizados pela homogeneização cultural e econômica (SILVA, 2014, p. 132).

Além do mais, a Constituição da Bolívia, promulgada em 2009, traz no preâmbulo a predominância pela busca do bem viver, baseada no respeito por sua história de luta, pela sagrada Madre Tierra e pela diversidade de culturas, inspiração para a construção de um novo Estado, que é unitário social de direito plurinacional comunitário, pelo povo boliviano.

Entre os princípios ético-morais previstos na Constituição, o artigo 8, I, do capítulo segundo, do título I, dispõe que o Estado assume e promove asuma qamaña (bem viver), a ñandereko (vida harmoniosa), a teko kavi (vida boa), a ivi maraei (terra sem mal) e o qhapaj ñan (caminho ou vida nobre), que refletem a cultura indígena do bem viver e da integração com o ambiente.

Também no artigo $8^{\circ}$, I e II destacam suas situações que materializam essa preocupação, respectivamente: a adoção, num cenário de pluralidade de nações indígenas, da nandereko (vida harmoniosa) e, como valores incorporado nas atividades realizadas pelo Estado.

Essas duas situações retratam o compromisso social e estatal de se buscar o sentido harmônico de convivência, fomentando, também, a busca de mecanismos capazes de concretizar esse fundamento constitucional elaborado pelo consenso popular (MAGRO; SIGNOR; AQUINO, 2018, p. 72). Nesse caso, tem-se caracterizado o meio axiológico desta Constituição para viabilizar, segundo seu artigo $9^{\circ}, 1$ a finalidade de: Constituir una sociedad justa y armoniosa, cimentada en la descolonización, sin discriminación ni explotación, con plena justicia social, consolidando las identidades plurinacionales (BOLIVIA, 2009).

Embora a Constituição da Bolívia não trate especificamente da natureza como sujeito de direitos, a natureza é abordada em textos infraconstitucionais por meio da Lei $\mathrm{n}^{\circ} 71$, de 2010 (Ley de derechos de la Madre Tierra), e da Lei $\mathrm{n}^{\circ}$ 300, de 2012 (Ley marco de la Madre Tierra y desarollo integral para vivir bien). Em outras palavras, consiste em uma relação de equilíbrio com a natureza, que não exclui o ser humano dessa visão; trata-se de uma 
verdadeira complementaridade, por meio da qual se reconhece o direito de todos os seres vivos a uma existência digna e o papel de todos para a manutenção da vida no planeta.

Acosta e Martínez (2011) alegam que o sentido do sumak kawsay é voltado para a ancestralidade andina, não sendo possível reproduzir esse princípio nos ordenamentos ocidentais. para os autores el sumak kawsay es el eje referencial de los derechos de la naturaleza, ou seja, para se alcançar o princípio do bem viver é preciso criar os direitos da natureza, como se depreende na leitura do art. 277 da Constituição da Bolívia.

Neste contexto, cabe pontuar que as duas terminologias: Suma Qamaña e Sumak Kawsay. Ambas dizem respeito à cosmovisão dos povos originários altiplanos, cujo ideário não deve se limitar apenas ao estilo de vida de Nações Indígenas. Isso porque constitui uma sugestão de pensar outra nova realidade, apoia-se na imprescindibilidade da (con)vivência em harmonia entre seres humanos e Pacha Mama - a Terra. Em tal perspectiva não deve imperar comparação, competição e subsequentemente acumulação, porém mantém-se o modelo de desenvolvimento entendido como crescimento econômico e progresso. Esses seriam os paradigmas do desenvolvimento versus buen viver (NASCIMENTO JÚNIOR, 2016).

Nesse sentido, é importante considerar que Constituições do Equador e da Bolívia representam mudanças significativas em vários sentidos: teórico, político, cultural, jurídico etc. e influenciam o (re)pensar da questão socioambiental a partir de novas compreensões da relação do ser humano e natureza, cada qual ao seu modo e em seu espaço, mas com seu legado teórico e social que marcam de novos significados o viver na "casa comum", o se relacionar com a Pacha Mama (OLIVEIRA; BLANCO TARREGA, 2018, p. 125).

Assim, tem-se que apesar de se fincarem em bases de pensamento diferentes, há um diálogo possível, pela proximidade de intenções, entre as Constituições do Equador e da Bolívia, pois superam o trivial e dão à natureza a compreensão e o lugar devidos, esclarecendo que o ser humano não se desvincula hora alguma do ambiente, do nascer ao morrer, estará embalado nos braços da Mãe-Terra (OLIVEIRA; BLANCO TARREGA, 2018, p. 126).

Nesse contexto, observa-se que a natureza se encontra em estado de total vulnerabilidade, estando seus direitos atrelados às necessidades humanas, sendo no sistema jurídico brasileiro, apenas um ser inanimado e semovente. Importante registrar que, no Brasil, não houve nenhum movimento social com grande representatividade, como no Equador e na Bolívia, a ponto de modificar os direitos da natureza (SEGNINI, 2018, p. 31-33). 
Há que se ter em mente que, ao se atribuir personalidade jurídica ao meio ambiente (ou a seus elementos), se reconhecem os direitos do meio ambiente de existir separado do seu valor para o ser humano. Trata-se de seu intrínseco, ou seja, seu valor em si e por si mesmo, independentemente do uso ou da função que possa ter na relação com outrem, incluindo o homem. A personalidade jurídica dará aos bens ambientais vários direitos. O tipo e a extensão desses direitos poderão ser discutidos pela sociedade e pelos gestores (ou representantes do bem). Podem ser direitos gerais e direitos específicos, variando de acordo com o bem ambiental (TOZZI, 2018).

Também, reconhecer os direitos dos bens ambientais envolve restrições de práticas ou atividades que podem ser consideradas como destrutivas ou indesejadas, que podem comprometer o frágil equilíbrio do ecossistema. Obviamente, mesmo que concedido ao bem ambiental o direito de, juridicamente, existir e se desenvolver, isso não significa que atividades não possam ser desenvolvidas, como o turismo, o lazer, as pesquisas científicas, entre outros (TOZZI, 2018).

A mudança de paradigmas e conscientização da sociedade é algo indispensável para que realmente se possa anunciar que a maior riqueza tida pela humanidade é e sempre será aquelas retiradas da natureza. Os recursos naturais possuem valor imensurável e devem ser vistos como tal, afinal a natureza não precisa do homem para gerar suas riquezas ou continuar existindo, contudo, a recíproca não é verdadeira (GOMES; PAZINATO, 2018, p. 164).

\section{O PRINCÍPIO 10 DA DECLARAÇÃO DO RIO SOBRE MEIO AMBIENTE E DESENVOLVIMENTO}

O Princípio 10 é um dos compromissos assumidos pelos Governos na Declaração da Conferência Rio-92 sobre Meio Ambiente e Desenvolvimento para assegurar o acesso à participação, à informação e à justiça nas questões ambientais, bem como para estimular a conscientização e a participação popular, a disponibilização de informações e o funcionamento de mecanismos judiciais e administrativos, inclusive no que se refere à compensação e reparação de danos ao meio ambiente (FREITAS; BRASIL, 2018, p. 120)

Após vinte anos da Conferência, durante a Rio+20, um grupo de países da América Latina e do Caribe deflagrou um processo para promover a aplicação desse princípio que trata do acesso à participação, à justiça e à informação em temas ambientais. 
Assim está redigido o princípio 10 da declaração de meio ambiente e desenvolvimento:

\begin{abstract}
A melhor maneira de tratar as questões ambientais é assegurar a participação, no nível apropriado, de todos os cidadãos interessados. No nível nacional, cada indivíduo terá acesso adequado às informações relativas ao meio ambiente de que disponham as autoridades públicas, inclusive informações acerca de materiais e atividades perigosas em suas comunidades, bem como a oportunidade de participar dos processos decisórios. Os Estados irão facilitar e estimular a conscientização e a participação popular, colocando as informações à disposição de todos. Será proporcionado o acesso efetivo a mecanismos judiciais e administrativos, inclusive no que se refere à compensação e reparação de danos - Princípio $10 \mathrm{da}$ Declaração do Rio Sobre Meio Ambiente e Desenvolvimento.
\end{abstract}

O Princípio 10 é conhecido como o princípio da democracia ambiental. Assegura a participação do cidadão nas instâncias de decisões dos governos sobre as questões ambientais e o acesso à informação e à justiça, nesses temas. Além disso, fica estabelecido o compromisso dos governos em garantir aos cidadãos a participação social, o acesso à informação e o acesso à Justiça nessas questões.

Diversos países latino-americanos e caribenhos se comprometeram em elaborar um Plano de Ação, com apoio da CEPAL (Comissão Econômica para a América Latina e o Caribe), para ajudar na implementação do Princípio 10 em seus territórios. Com isso, busca-se a efetivação desse princípio para tornar cada informação de que disponha às autoridades públicas, relativa ao meio ambiente, disponível a todos os cidadãos interessados (ARTIGO 19, 2011)

O acesso à informação motiva a população a participar nas tomadas de decisões do governo que, por sua vez, consegue de maneira mais efetiva responder às demandas das comunidades e aumentar a aceitação e o cumprimento das medidas ambientais.

Há um reconhecimento crescente, tanto pela sociedade civil quanto pelos governos que o acesso à informação, participação e justiça em questões ambientais é fundamental para alcançar a protecção ambiental eo desenvolvimento sustentável. Para este fim, foi sugerido que os países da América Latina e do Caribe devem avançar numa política com base em uma informação mais participativa (CEPAL, 2013, p. 27).

O objetivo maior que permeia a implantação do referido Princípio 10 é permitir que pessoas recebam informações do Estado em tempo hábil e participem desde o início de 
processos de tomada decisão que envolvam a execução de políticas governamentais e/ou a realização de empreendimentos que causem impactos socioambientais.

Devido ao contexto regional de ameaças ao meio ambiente, desequilíbrios ecológicos e descaso com populações vulneráveis, o acordo regional é uma importante oportunidade para melhorar a garantia do acesso à informação, participação e acesso à justiça nas questões ambientais, também chamados de direitos de acesso. Tais direitos são fundamentais para a prevenção de conflitos e para a judicialização de fatos que comprometem a qualidade ambiental e integridade dos serviços e bens ecossistêmicos (IMAFLORA, 2015).

Adotar de forma efetiva as diretrizes desse princípio no Brasil permitiria a todos os cidadãos reivindicar um desenvolvimento socioeconômico mais sustentável, com conservação ambiental e consciência sobre os impactos de obras em dezenas de regiões, além de garantir uma participação mais efetiva da sociedade na discussão dos temas ambientais. Por isso, necessário abordar o alcance desses direitos de acesso.

\section{CONSIDERAÇÕES FINAIS}

Como resultado da pesquisa, claro está que conceder personalidade jurídica à natureza, como fez o Equador e a Bolívia, acarreta sim consequências diversas das atuais na linha de defesa do meio ambiente.

Nessa perspectiva, o Direito enquanto "(...) saber teórico e prático vinculado às culturas humanas" deve se apropriar de novos modelos de pensamento, situando-se como ciência social aplicada, compreendendo que o conhecimento jurídico "(...) deve ser um conhecimento que leva em consideração as necessidades teóricas e práticas de uma determinada sociedade e de seus indivíduos". Desse modo, o refletir sobre o Direito, deve, então, pensar e agir sobre a realidade "(...) e seu resultado deve configurar-se como uma possibilidade de interferência na própria realidade" (CAMILLOTO, 2016, p. 53)

Assim, aPacha Mama abarca o princípio do buen vivir, de cunho indígena, e entendem que essa forma de proteção - em que a natureza tem o direito de ter seu 
desenvolvimento respeitado - pode vir a garantir a redução das desigualdades sociais e econômicas. Por seu turno, o Brasil garante a proteção ambiental às futuras gerações, ou seja, a natureza deve ser preservada para fins de sobrevivência humana (BARBOSA; PEREIRA, 2015, p. 2).

\section{REFERÊNCIAS}

ACOSTA, Alberto. Bitácoraconstituyente: ¡todo para laPatria, nada para nosotros! Quito: EdicionesAbya-Yala, 2008.

ACOSTA, Alberto; MARTÍNEZ, Esperanza (Comp.). La Naturaleza con derechos: de la filosofía a la política. Quito: Ediciones Abya-Yala, 2011, p. 317-362. Disponível em: http;//www.rosalux.org.ec/attachments/article/254/derechos-naturaleza.pdf. Acesso em: 23 dez. 2018.

ANTEQUERA, Jesús Conde. El deber jurídico de restauración ambiental. Granada: Editorial Comares, 2004

ANTUNES, Paulo de Bessa. Direito ambiental. 15. ed. São Paulo: Atlas, 2013.

ARKONADA, Katu; et al. Un estado, muchos pueblos: la construcción de la plurinacionalidad en Bolivia y Ecuador. Barcelona: Icaria, 2012.

ARTICLE 19/The Access Initiative (2011), Moving from principles to rights. Rio 2012 and ensuring access to information, public participation, and access to justice for everyone", julio [en línea]. Disponível em:

http://www.accessinitiative.org/sites/default/files/Moving\%20from\%20Principles\%20to\%20R ights.pdf. Acesso em: 06 jan. 2020.

BAHIA, Cláudio José Amaral; TOLEDO, Cláudia Mansani Queda de; TOLEDO, Flávio Euphrásio Carvalho de. Pacha Mama: la madre Tierra e a ressignificação da tutela da dignidade humana em face do novo constitucionalismo da América Latina. In: Revista Direitos Culturais, Santo Ângelo-RS, v. 13, n. 3, p. 127-151, set./dez., 2018.

BARBOSA, Caroline Camargo; PEREIRA, Tatiana Cotta Gonçalves. A natureza como sujeito de direitos no novo constitucionalismo latino-americano e o princípio do bem viver. In: III Reunião anual de iniciação científica da UFRRJ: trabalho, desenvolvimento e sustentabilidade, Seropédica, 2015.

BOFF, Leonardo. Sustentabilidade: o que é, o que não é. Petrópolis: Vozes, 2013.

BOLIVIA. Constitución Política del Estado Plurinacional de Bolivia. Disponível em: https://www.oas.org/dil/esp/Constitucion_Bolivia.pdf. Acesso em 04 nov. 2018. 
BRAUNER, Maria Claudia Crespo; LIEDKE, Mônica Souza; SCHNEIDER, Patrícia Maria. Biotecnologia e direito ambiental: possibilidades de proteção da vida a partir do paradigma socioambiental. Jundiaí: Paco Editorial, 2012.

BRASIL. Constituição da República Federativa do Brasil (1988). Promulgada em 05 de outubro de 1988. Disponível em:

http://www.planalto.gov.br/ccivil_03/Constituicao/Constituicao.htm. Acesso em: 30 dez. 2018.

BRASIL. Lei $\mathbf{n}^{\mathbf{0}}$ 6.938, de 31 de agosto de 1981. Dispõe sobre a Política Nacional do Meio Ambiente, seus fins e mecanismos de formulação e aplicação, e dá outras providências. Disponível em: http://www.planalto.gov.br/ccivil_03/Leis/L6938.htm. Acesso em: $30 \mathrm{dez}$. 2018.

CAMARGO, Alfred José Cavalcanti Jordão de. Bolívia: a criação de um novo país a ascensão do poder político autóctone das civilizações pré-colombianas a Evo Morales. Brasília: Ministério das Relações Exteriores, 2006.

CAMILLOTO, Bruno. Direito, democracia e razão pública. Belo Horizonte: Editora D'Plácido, 2016.

CLAVERO, Bartolomé. Derecho global: por una historia verosímil de los derechos humanos. Madrid: Editorial Trotta, 2014.

DIMOULIS, Dimitri. Manual de introdução ao estudo do direito: definição e conceitos básicos, norma jurídica. 5 ed. rev. atual e ampl. São Paulo: Editora Revista dos Tribunais, 2013.

ECUADOR. Constitución del Ecuador. Asamblea Constituyente. Disponível em: http://www.asambleanacional.gov.ec/documentos/constitucion_de_bolsillo.pdf. Acesso em 04 nov. 2018.

ECUADOR. Código Orgánico General de Procesos, de 22 de mayo de 2015. Disponível em: http://www.funcionjudicial.gob.ec/pdf/CODIGO \%20ORGANICO \%20GENERAL20DE \%PROCESOS.pdf. Acesso em: 28 dez. 2018.

FACHIN, Luz Edson. Teoria crítica do direito civil: à luz do novo código civil brasileiro. 3. ed. Rio de Janeiro: Renovar, 2012.

FREITAS, Érica Patrícia Moreira; BRASIL, Deilton Ribeiro. Garantia dos direitos de acesso para uma efetiva democracia ambiental. In: CAMPELLO, Lívia GaigherBósio; SOUZA, Maria Cláudia Antunes; RIBEIRO, Mariana Santiago [org.] Meio ambiente e desenvolvimento:os 25 anos da Declaração do Rio-92. 1. ed. São Paulo-SP: Instituto de Desenvolvimento Humano Global-IDG, 2018, v. 1, p. 118-126.

GARZÓN, Rene Patricio Bedón. Aplicación de los derechos de la naturaleza en Ecuador. In: Revista Veredas do Direito. Belo Horizonte, v. 14, n. 28, p. 13-32, jan./abr. 2017. 
Disponível em:

http://www.domhelder.edu.br/revista/index.php/veredas/article/view/1038/537. Acesso em: 28 jan. 2020.

GOMES, Carolina Balesquem de Oliveira; PAZINATO, Liane Francisca Huning. Pelo fim da visão antropocêntrica para realização da justiça socioambiental e reconhecimento da natureza como riqueza da humanidade. In: CAOVILLA, Maria Aparecida Lucca; RENK, Arlene (Orgs.) Pluralismo Jurídico, Constitucionalismo Latino-Americano, Buen Vivir e os Direitos da Natureza. III Congresso Internacional. v. 1, e-book, São Leopoldo: Karywa, 2018, p. 156-166.

GRANZIERA, Maria Luiza Machado. Direito Ambiental. São Paulo: Atlas, 2009.

GUSSOLI, Felipe Klein. A natureza como sujeito de direito na Constituição do Equador: considerações a partir do caso Vilacamba. In: Anais da XVI Jornada de Iniciação Científica. Curitiba, v. 1. p. 1-172, 2014.

ILLICH, Ivan. La convivencialidad. Tradução de Matea P. De Gossmann. Barcelona: Barral Editores, 1974.

IMAFLORA. Democracia Ambiental e Princípio 10 no Brasil: panorama, estudos de caso e o potencial do acordo regional, realizado pelo Imaflora e Artigo 19. São Paulo, 2015.

LANDER, Edgardo. Ciências Sociais: saberes coloniais e eurocêntricos. In: LANDER, Edgardo [Org.]. A colonialidade do saber: eurocentrismo e ciências sociais - perspectivas latino-americanas. Buenos Aires: CLACSO, 2005, p. 8-23.

LATOUCHE, Serge. Survivre au développement: de la décolonisation de l'imaginaire économique à la construction d'une société alternative. Paris: Mille et Une Nuits, 2004.

LEITE, José Rubens Morato (coord.). Manual de direito ambiental. São Paulo: Saraiva, 2015.

LEONEL JÚNIOR, Gladstone. O novo constitucionalismo latino-americano: um estudo sobre a Bolívia. Rio de Janeiro: Lumen Juris, 2015.

MAGRO, Diogo Dal; SIGNOR, Giulia; AQUINO, Sérgio de. Princípio da harmonia: processo constituinte da Bolívia e a efetividade da sustentabilidade. In: CAOVILLA, Maria Aparecida Lucca; RENK, Arlene (Orgs.) Pluralismo Jurídico, Constitucionalismo LatinoAmericano, Buen Vivir e os Direitos da Natureza. III Congresso Internacional. v. 2, e-book, São Leopoldo: Karywa, 2018, p. 63-76.

MANCE, Euclides André. Bem viver. In: SIDEKUM, A.; WOLKMER, A. C.; RADAELLI, S. M. (Orgs.). Enciclopédia Latino-Americana de Direitos Humanos. Blumenau: Edifurb; Nova Petrópolis: Nova Harmonia, 2016.

MONTEIRO, Nathielen Isquierdo; PONTES, Thaís da Costa Abrão; WIENKE, Felipe Franz. Reflexões sobre a perspectiva da natureza como sujeito de direitos: contribuição para uma visão biocêntrica. In: CAOVILLA, Maria Aparecida Lucca; RENK, Arlene (Orgs.) 
Pluralismo Jurídico, Constitucionalismo Latino-Americano, Buen Vivir e os Direitos da Natureza. III Congresso Internacional. v. 2, e-book, São Leopoldo: Karywa, 2018, p. 20-32.

NAESS, Arne. Deep Ecology. In: MERCHANT, Carolyn. Key concepts in critical theory: ecology. AtlanticHighlands: Humanities Press, 1994, p. 120-124.

NASCIMENTO JÚNIOR. Wanderley dos Reis Nascimento Júnior. O paradigma do "vivir bien" no Estado plurinacional da Bolívia como referente para a construção de políticas públicas emancipatórias. In: Revista Brasileira de Políticas Públicas e Internacionais. Disponível em:

file:///C:Users/marce/AppData/Local/Packages/MicrosoftEdge_8wekyb3d8bbwe/TempState/ Downloads/28245-66691-1-PB\%20(3).pdf . Acesso em: 29 dez. 2018.

OLIVEIRA, Daniel Gonçalves de; BLANCO-TARREGA, Maria Cristina Vidotte. Um diálogo entre o novo constitucionalismo latino-americano e a Encíclica Laudato Si: para além do discurso hegemônico do direito. In: Direitos da Natureza II [Recurso eletrônico on-line] organização CONPEDI/ UASB Coordenadores: Norma Sueli Padilha; Cristiane Derani; Fernando Antonio de Carvalho Dantas. - Florianópolis: CONPEDI, 2018. Disponível em: https://www.conpedi.org.br/publicacoes/5d6x83my/9lge9803/4SrGCibN53x6d0S3.pdf. Acesso em: 29 dez. 2018.

OLIVEIRA, Fábio Corrêa Souza de. Direitos da natureza e direito dos animais: um enquadramento. Revista do Instituto de Direito Brasileiro. a. 2. n. 10. p. 11325-11370. Lisboa, 2013. Disponível em: http://www.fd.ulisboa.pt/investigacao/producaocientifica/revistas-cientificas/revista-da-fdul/. Acesso em 23 jan. 2020.

POLI, Luciana Costa. Buen vivir: uma alternativa para o desenvolvimento sustentável. In: MIRANDA, Jorge; GOMES, Carla Amado [Coord.], CAÚLA, Bleine Queiroz; CARMO, Valter Moura do [Orgs.]. Diálogo ambiental, Constitucional e Internacional. Lisboa: Instituto de Ciências Jurídicos-Políticas, v. 3, t. II, out.- 2015, p. 19-39.

QUIJANO, Aníbal. Colonialidad y Modernidad-racionalidad. In: BONILLO, Heraclio [Comp.]. Los conquistados. Bogotá: Tercer Mundo Ediciones, FLACSO, 1992, p. 437-449.

SANTOS, Boaventura de Sousa. Reconhecer para libertar: os caminhos do cosmopolitismo cultural. Porto: Afrontamento, 2004.

SEGNINI, Carolina Cammarosano. A natureza como sujeito de direitos e o direito à vida: reflexões à luz da Constituição Equatoriana e Brasileira. In: Direitos da Natureza I [Recurso eletrônico on-line] organização CONPEDI/ UASB Coordenadores: Elcio Nacur Rezende; Maria Augusta León. - Florianópolis: CONPEDI, 2018, p. 23-40.

SILVA, Heleno Florindo da. Teoria do Estado plurinacional: o novo constitucionalismo latino-americano e os direitos humanos. Curitiba: Juruá Editora, 2014.

STEIGLEDER, Annelise Monteiro. Responsabilidade civil ambiental: as dimensões do dano ambiental no Direito brasileiro. Porto Alegre: Livraria do Advogado, 2011. 